\title{
EFEITO DA SEMEADURA A SECO E TRATAMENTO DE SEMENTES NA EMERGÊNCIA, RENDIMENTO DE GRÃOS E OUTRAS CARACTERÍSTICAS DA SOJA [Glycine max (L.) Merrill]
}

\author{
PEDRO MILANEZ DE REZENDE ${ }^{1}$ \\ JOSÉ DA CRUZ MACHADO ${ }^{2}$ \\ CRISTIANE FORTES GRIS ${ }^{3}$ \\ LEONARDO LINO GOMES ${ }^{3}$ \\ ÉLBERIS PEREIRA BOTREL ${ }^{4}$
}

\begin{abstract}
RESUMO - O trabalho foi conduzido na Universidade Federal de Lavras-MG, em um Latossolo Roxo distrófico, no ano agrícola 94/95. Utilizou-se o delineamento blocos casualizados em esquema fatorial $2 \times 4$, compreendendo: semente tratada com fungicida Vitavax/Thiram P.M.e não tratada, e quatro períodos de seca $(0,7,14$ e 21 dias após a semeadura). A semeadura foi realizada em solo seco ( $6 \%$ de umidade), uti-
\end{abstract}

lizando-se a cultivar Doko. As sementes apresentaram ótima performance até 14 dias, não sendo alterado o rendimento de grãos, proporcionando ao agricultor uma maior elasticidade na data da semeadura. Os tratamentos fungicidas, por sua vez, apesar de alterarem significativamente o estande inicial e final, não proporcionaram aumentos no rendimento de grãos.

TERMOS PARA INDEXAÇÃO: Tratamento químico, semeadura no seco, soja, Glycine max.

\section{EFFECT OF DRY SOIL SOWING AND SEEDS TREATMENT ON EMERGENCE, YIELDS GRAINS AND OTHER CHARACTERISTICS OF SOYBEAN}

\begin{abstract}
The experiment was carried out at Federal Universidade of Lavras, on a soil classified as Distrophic Dusky Latosol in the agricultural year 94/95. The experimental design was a randomized blocks in factorial scheme $2 \times 4$ : treated seeds with fungicides Vitavax/Thiram P.M.; and untreated seeds and four time of dry $(0,7,14$ and 21 days after sowing). The sowing was realized in dry soil $(6 \%$ moisture
\end{abstract}

content), using the Doko cultivar. The soybean seeds sowed in the dry soil, presented great performance up to 14 days, not being altered the grains yields, providing to the farmer a larger flexibility in the sowing date. Although, the fungicides treatments, altered the initial and final stand significantly, they did not provide increases in the grains yields.

INDEX TERMS: Chermical treatment, sowing dry, soybean, Glycine max.

\section{INTRODUÇÃO}

A alta produtividade das culturas depende diretamente da qualidade das sementes utilizadas na semeadura. O desempenho dessas sementes está relacionado com o histórico de sua produção, processamento e as condições de ambiente que encontra no solo.
No processo produtivo, nem sempre a semeadura, a colheita e o armazenamento podem ser conduzidos na época adequada, tornando o problema de incidência de patógenos nas sementes de difícil solução. Nessa situação, a obtenção de sementes de soja isentas de rachaduras ou trincas no tegumento é praticamente impossível, pois na colheita elas passam por uma série de

1. Engenheiro Agrônomo, Dr., Professor Titular do Departamento de Agricultura da UNIVERSIDADE FEDERAL DE LAVRAS/UFLA, Caixa Postal 37, 37200-000 - Lavras, MG. pmrezend@ufla.br, Bolsista do CNPq.

2. Engenheiro Agrônomo, PhD, Professor Titular do Departamento de Fitopatologia/UFLA, Bolsista do CNPq.

3. Acadêmicos do $9^{\circ}$ período do Curso de Agronomia da UFLA.

4. Pós-graduando, Curso de Doutorado em Fitotecnia-UFLA. 
impactos que afetam a qualidade. Após a semeadura, essas rachaduras facilitam a penetração de patógenos, reduzindo os valores de germinação em laboratório, conforme salientam Moraes (1980), Soave \& Wetzel (1987), Carbonell \& Krzyzanowski (1993) e Brito et al. (1996).

As sementes de soja podem transportar diversos fungos patogênicos responsáveis por perdas consideráveis à cultura. De acordo com Yorinori (1977), cerca de 75 patógenos podem ser transmitidos pelas sementes. A melhor estratégia de controle das doenças é a prevenção, mediante uso de sementes sadias, cultivares resistentes e tratamento químico das sementes. De acordo com Athow \& Caldwell (1976) e Maggione \& Sanchez (1976), essa prática é recomendável especialmente para sementes de baixa germinação, cuja causa principal são os patógenos a ela associados, ocasionando, assim, diminuição no potencial de inóculo e, conseqüentemente, aumento na porcentagem de emergência das plântulas.

Em trabalhos realizados com tratamento de sementes, tem-se demonstrado maior eficiência quando utilizado em sementes com germinação abaixo de $70 \%$ e alta incidência de patógenos (Ellis \& Paschal,1975). Alguns autores, no entanto, relatam aumento da emergência também para sementes de alta qualidade, quando tratadas com fungicidas. Assim, Pereira et al. (1993) e Adkins et al. (1996) evidenciaram que o tratamento das sementes de boa qualidade é economicamente viável, se essa semente for utilizada em condições ambientais desfavoráveis, predispondo-a aos fungos da semente ou do solo. Resultados similares foram observados por Nasser et al. (1984) e Henning et al. (1991), que também constataram o efeito benéfico do tratamento de sementes no controle de fungos existentes na semente e no solo.

A época de semeadura da soja é uma das práticas que pode alterar significativamente a produtividade dessa cultura, uma vez que a mesma é sensível ao fotoperíodo. Na maioria dos casos, essa prática fica condicionada à presença de umidade no solo originária de precipitações pluviométricas, uma vez que maior parte da área plantada de soja no Brasil não é realizada com auxílio de irrigação. Na expectativa do adequado teor de umidade no solo, o agricultor, na maioria das vezes, atrasa a semeadura. Mediante o problema exposto, uma alternativa é o plantio em solo com baixo teor de umidade, ficando a germinação das sementes na dependência das chuvas iniciais.

Nessa situação, um problema grave a ser enfrentado pelas sementes é a temperatura e o período em dias de armazenamento das sementes no solo, o que poderia se agravar para sementes de soja, dado o seu alto teor de óleo.

Evidências do efeito da temperatura em sementes de soja têm sido comprovadas em alguns trabalhos. Miranda et al. (1979) submeteram sementes de diferentes cultivares à temperatura de $48^{\circ} \mathrm{C}$, condicionadas em tubos de ensaio por um período de $0,2,4,6,8,10$ e 12 dias. Esses autores verificaram que à medida que se aumentou o tempo de exposição das sementes, ocorreu um decréscimo mais acentuado na germinação e aumento da taxa de necrose dos cotilédones para todas as cultivares testadas, passando de $92 \%$ no tratamento testemunha, para $32 \%$ com o maior tempo de exposição, o que foi posteriormente confirmado por Falivene et al. (1980) e Helms et al. (1996), que também constataram queda na emergência por efeito do aumento de temperatura e estresse hídrico provocado pela secagem do solo.

Em se tratando do aspecto de armazenamento, Pereira et al. (1985) demonstraram em experimento em campo o efeito em sementes de soja submetidas a tratamentos com fungicidas Thiram e/ou Estreptomicina, por três anos consecutivos, semeadas em solo com baixo teor de umidade. Verificaram os autores que a presença do fungicida Thiram induziu sempre a uma melhor emergência, proporcionando proteção às sementes em solo com baixa disponibilidade hídrica por períodos de 4 a 12 dias, dependendo do nível de vigor das sementes utilizadas. Mais recentemente, Brito et al. (1996), em ensaio em casa-de-vegetação utilizando óleo mineral como protetor de sementes, dois níveis de umedecimento do solo ( $80 \%$ da capacidade de campo e solo seco por 6 dias) e sementes danificadas, constataram que os danos mecânicos na semente e a condição de solo seco por 6 dias, isoladamente, foram responsáveis pela diminuição da emergência e do índice de velocidade de emergência.

Em conseqüência desses fatores e da debilidade natural das sementes de soja de natureza morfológica e fisiológica, inúmeros pesquisadores têm concentrado esforços com o objetivo de atenuar ou de solucionar problemas, dirigindo estudos ao controle de qualidade, deterioração, colheita, armazenamento e tratamento de sementes em benefício do seu comportamento após a semeadura.

Dessa maneira, a germinação das sementes representa a meta prioritária dentro do processo de produção, justificando o presente trabalho, com o qual objetiva-se estudar o efeito da semeadura a seco e do tratamento de sementes com fungicidas na emergência, rendimento de grãos e outras características da soja (Glycine $\max (\mathrm{L}$.) Merrill). 


\section{MATERIAL E MÉTODOS}

O ensaio foi instalado no ano agrícola de 1994/95, em solo classificado como Latossolo Roxo distrófico de textura argilosa, fase cerrado, do campus experimental da Universidade Federal de Lavras (MG), situada a 918,80 m de altitude, latitude de $21^{\circ} 14^{\prime}$ e longitude $45^{\circ} 00 \mathrm{w}$. O clima da região, na classificação de Köppen, é do tipo $\mathrm{Cwb}$, com temperatura média de $22,1^{\circ} \mathrm{C}$ no mês mais quente e $15,8^{\circ} \mathrm{C}$ no mês mais frio, sendo a precipitação média anual de $1530 \mathrm{~mm}$, com uma evaporação total no ano de 1043,3 mm e umidade média anual de 76,2\% (Brasil, 1992). As variações de temperatura e precipitação média diária ocorridas durante a condução do experimento estão apresentados na Figura 1.

A amostra de solo foi coletada na camada de 0$20 \mathrm{~cm}$ de profundidade, apresentando as seguintes características químicas: $\mathrm{pH}$ em água $=5,5, \mathrm{P}=5$ $\mathrm{mg} / \mathrm{dm}^{3}, \mathrm{~K}=147 \mathrm{mg} / \mathrm{dm}^{3}, \mathrm{Ca}=2,8 \mathrm{cmolc} / \mathrm{dm}^{3}, \mathrm{Mg}=$ $0,1 \mathrm{cmolc} / \mathrm{dm}^{3}, \mathrm{Al}=0,1 \mathrm{cmolc} / \mathrm{dm}^{3}$, matéria orgânica $=31 \mathrm{dag} / \mathrm{dm}^{3}$ e texturais: areia $=36 \%$, limo $=33 \%$ e argila $31 \%$.

O delineamento experimental utilizado foi o de blocos casualizados em esquema fatorial $2 \times 4$, com- preendendo: semente tratada e não tratada com fungicida e quatro períodos de seca $(0,7,14$ e 21 dias após semeadura ). Foi utilizada a cultivar Doko, que apresentou germinação de $85 \%$ e vigor (envelhecimento precoce) de $58 \%$, sendo as sementes tratadas com fungicida Vitavax/Thiran na dosagem de $200 \mathrm{~g} / 100 \mathrm{~kg}$ de sementes. A semeadura foi realizada em 11/10/94 em solo seco ( $6 \%$ de umidade), sendo mantido nessa situação com a cobertura de lona plástica para impedir a passagem de chuvas para as parcelas que iriam receber irrigações aos 7, 14 e 21 dias após semeadura. O tratamento (zero) 0 dias foi considerado testemunha, sendo semeado e irrigado no mesmo dia, mantendo-se, posteriormente, as condições favoráveis de germinação até emergência das plântulas.

As parcelas foram constituídas de quatro linhas de 5,0 $\mathrm{m}$ espaçadas de $0,5 \mathrm{~m}$. Para área útil, utilizaram-se as duas fileiras centrais, sendo eliminadas também a título de bordadura $0,5 \mathrm{~m}$ de cada extremidade. A fim de evitar interferência de irrigação de uma parcela para outra, as mesmas foram espaçadas de 2,0 m. O desbaste nas parcelas, quando necessário, foi realizado de acordo com Rezende et al. (1981), deixando-se 25 plantas por metro linear.

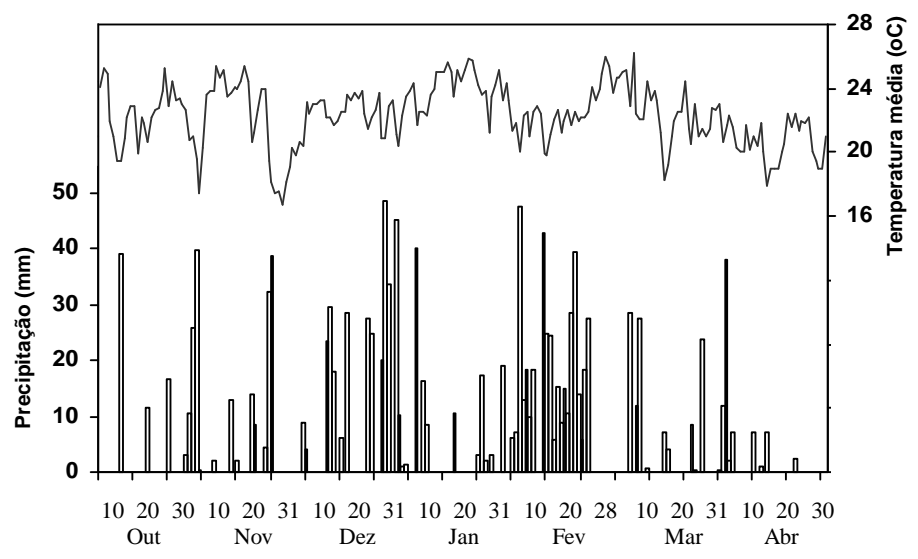

FIGURA 1 - Variação diária da temperatura média do ar e precipitação pluvial de outubro de 1994 a abril de 1995, UFLA, Lavras (MG) - (FONTE: ESTAÇÃO CLIMATOLÓGICA DE LAVRAS - MG). 
A calagem foi feita de acordo com análise do solo e todas as parcelas experimentais receberam na semeadura adubação básica de $90 \mathrm{~kg}$ de $\mathrm{P}_{2} \mathrm{O}_{5}$ e $20 \mathrm{~kg}$ de $\mathrm{K}_{2} \mathrm{O}$ por ha, nas formas de superfosfato simples e cloreto de potássio, de acordo com a Comissão... (1989).

As sementes, após o tratamento com fungicida, foram inoculadas com o Bradyrhizobium japonicum na dosagem de $200 \mathrm{~g} / 40 \mathrm{~kg}$ de sementes.

Durante a condução do ensaio, foram determinadas as seguintes características:

a) Rendimento de grãos obtidos em cada parcela, corrigindo-se a umidade dos grãos para $13 \%$ e fazendose, posteriormente, a conversão para $\mathrm{kg} / \mathrm{ha}$.

b) Estande inicial: determinado em todas as parcelas 20 dias após emergência, ocasião em que foi também realizado o desbaste.

c) Estande final: determinado em todas as parcelas por ocasião da colheita, contando-se todas as plantas existentes na área útil.

d) Altura da planta e da inserção da primeira vagem: medidas realizadas do colo ao ápice da planta e à ponta da primeira vagem em dez plantas ao acaso, na fileira útil de cada parcela, sendo o resultado expresso em $\mathrm{cm}$.

e) Índice de acamamento avaliado de acordo com a escala proposta por Bernard et al. (1965), com notas de 1 a 5 , correspondendo a 1 - todas as plantas eretas, e a 5- todas as plantas acamadas.

\section{RESULTADOS E DISCUSSÃO}

Pela Tabela 1, verifica-se que ocorreu efeito significativo em todas as características testadas, exceto altura da planta.

\section{Rendimento de grãos}

O rendimento de grãos foi influenciado significativamente apenas pelos períodos de seca (Tabela 2). Observando-se essa tabela, pode-se verificar que a semente de soja pode ser mantida no campo (plantio a seco) por um período de até 14 dias, sem perdas na sua produtividade. Por outro lado, a manutenção da semente no solo por períodos mais prolongados, 21 dias, proporcionou perdas significativas na ordem de $22,2 \%$ (572 kg/ha), quando comparada à testemunha (semeada e irrigada no mesmo dia), o que concorda com trabalhos de outros pesquisadores (Pereira et al., 1985 e Brito et al., 1996), que também constataram a resistência da semente de soja ao armazenamento no solo seco em períodos que variaram de 4 a 12 dias.

Esses resultados são satisfatórios, uma vez que o sojicultor poderá obter algumas vantagens, tais como: maior facilidade na semeadura, menor risco de perda total de plantio por deficiência de umidade e maior concentração da semeadura dentro da época ideal. A prática da semeadura no seco vem sendo utilizada já há alguns anos na cultura do milho, sem maiores problemas. $\mathrm{Na}$ cultura da soja, alguns agricultores já faziam uso dessa técnica sem nenhum embasamento científico, e de acordo com a maioria deles, a semeadura de soja suportava essa situação por um período de 7 a 10 dias, o que foi comprovado no presente trabalho. Um inconveniente dessa prática é a presença de chuvas de menor intensidade, que poderia provocar o início do processo de germinação da semente. Não havendo umidade suficiente para a continuação do processo, essas plantas não conseguiram emergir, causando drásticas reduções no estande.

TABELA 1 - Resumo da análise de variância para o rendimento de grãos, estande inicial e final, altura da planta e inserção da $1^{\underline{a}}$ vagem, obtidos no ensaio semeadura a seco x fungicidas, ano agrícola 1994/95, UFLA, Lavras MG.

\begin{tabular}{|c|c|c|c|c|c|c|}
\hline \multirow{3}{*}{ Causa de Variação } & \multirow{3}{*}{ G.L } & \multirow{3}{*}{ Grãos } & \multicolumn{4}{|c|}{ Quadrados Médios } \\
\hline & & & \multicolumn{2}{|c|}{ Estande } & \multirow[b]{2}{*}{ Altura da Planta } & \multirow{2}{*}{$\begin{array}{c}\text { Altura Inserção } \\
1^{\text {a }} \text { vagem }\end{array}$} \\
\hline & & & Inicial & Final & & \\
\hline Blocos & 2 & $19.295,04$ & 0,99 & 0,18 & 174,04 & 5,54 \\
\hline Período Seco (Dias) & 3 & $557.116,27 * *$ & $144,99 * *$ & $40,59 * *$ & 80,50 & $261,15^{* *}$ \\
\hline Trat. Fung (F) & 1 & 24,00 & $85,04 * *$ & $42,97 * *$ & 130,67 & $84,37 * *$ \\
\hline Fung. X Dias & 3 & $49.082,77$ & $30,23 * *$ & $18,69 * *$ & 39,44 & $72,37 * *$ \\
\hline Resíduo & 14 & $69.799,89$ & 0,40 & 0,20 & 71,94 & 11,35 \\
\hline $\mathrm{CV}(\%)$ & & 11,09 & 3,67 & 3,36 & 11,17 & 11,64 \\
\hline
\end{tabular}


TABELA 2 - Resultados médios do rendimento de grãos, estande inicial e final, altura da planta e da inserção da $1^{\text {a }}$ vagem, obtidos no ensaio semeadura a seco x fungicidas, ano agrícola 1994/95, UFLA, Lavras MG*.

\begin{tabular}{|c|c|c|c|c|c|c|}
\hline \multirow{2}{*}{$\begin{array}{l}\text { Tratamento } \\
\text { Fungicida }\end{array}$} & \multirow{2}{*}{$\begin{array}{l}\text { Período Seco } \\
\text { (Dias) }\end{array}$} & \multirow{2}{*}{$\begin{array}{l}\text { Grãos } \\
\text { Kg/ha }\end{array}$} & \multicolumn{2}{|c|}{ Estande } & \multicolumn{2}{|c|}{ Altura (cm) } \\
\hline & & & Inicial & Final & Planta & Inserção1 ${ }^{\text {a }}$ vagem \\
\hline \multirow{4}{*}{ Tratado } & 0 & 2497 & $488 \mathrm{a}$ & $240 \mathrm{a}$ & 78 & $34 \mathrm{a}$ \\
\hline & 7 & 2537 & $414 b$ & $240 \mathrm{a}$ & 77 & $31 \mathrm{ab}$ \\
\hline & 14 & 2659 & $344 \mathrm{c}$ & $213 a b$ & 82 & $32 \mathrm{ab}$ \\
\hline & 21 & 2128 & $246 \mathrm{~d}$ & $187 \mathrm{~b}$ & 75 & $26 \mathrm{~b}$ \\
\hline \multirow{8}{*}{ Não tratado } & 0 & 2649 & $471 \mathrm{a}$ & $231 \mathrm{a}$ & 78 & $34 \mathrm{a}$ \\
\hline & 7 & 2640 & $418 \mathrm{a}$ & $231 \mathrm{a}$ & 77 & $32 \mathrm{a}$ \\
\hline & 14 & 2666 & $173 \mathrm{~b}$ & $147 \mathrm{~b}$ & 75 & $30 \mathrm{a}$ \\
\hline & 21 & 1874 & $40 \mathrm{c}$ & $35 \mathrm{c}$ & 65 & $12 \mathrm{~b}$ \\
\hline & 0 & $2573 \mathrm{a}$ & $480 \mathrm{a}$ & $235 \mathrm{a}$ & 78 & $34 \mathrm{a}$ \\
\hline & 7 & 2589 a & $416 \mathrm{~b}$ & $235 \mathrm{a}$ & 77 & $31 \mathrm{a}$ \\
\hline & 14 & $2663 \mathrm{a}$ & $259 \mathrm{c}$ & $180 \mathrm{~b}$ & 78 & $31 \mathrm{a}$ \\
\hline & 21 & $2001 \quad b$ & $143 \mathrm{~d}$ & $111 \mathrm{c}$ & 70 & $19 \mathrm{~b}$ \\
\hline \multirow{2}{*}{$\begin{array}{c}\text { Tratado } \\
\text { Não tratado }\end{array}$} & & 2455 a & $373 \mathrm{a}$ & $220 \mathrm{a}$ & $78 \mathrm{a}$ & $31 \mathrm{a}$ \\
\hline & & $2457 \mathrm{a}$ & $276 \mathrm{~b}$ & $161 \mathrm{~b}$ & $74 \mathrm{a}$ & $27 \mathrm{~b}$ \\
\hline
\end{tabular}

* As médias seguidas pelas mesmas letras nas colunas não diferem estatisticamente entre si, pelo teste de Tukey, a $5 \%$.

Por outro lado, não foram constatadas diferenças significativas para o tratamento de sementes, o que concorda com trabalhos dos pesquisadores Ruschel \& Costa (1966) e Ellis \& Paschal (1975).

\section{Estande inicial e final}

Ao contrário do que ocorreu com o rendimento de grãos, essas características foram influenciadas significativamente pelos períodos de seca, fungicidas e interação período de seca x fungicidas (Tabela 1).

A interação período de seca $x$ tratamento fungicida para estande inicial, depois de desdobrada, mostrou que o tratamento das sementes proporcionou diferenças significativas na emergência das plantas. À medida que se aumentou o período de dias de armazenamento da semente no solo, ocorreu um decréscimo significativo na emergência das plantas (Tabela 2). Essa diminuição, entretanto, não comprometeu o estande inicial desejado por ocasião do desbaste de 25 plantas por metro linear, totalizando 250 plantas nas duas fileiras úteis, quando foi realizado o tratamento das sementes com fungicidas.

Entretanto, na ausência de tratamento de sementes, esse fato não ocorreu. Foi verificado um decréscimo na emergência das plantas, e nos tratamentos aos $14 \mathrm{e}$ 21 dias ocorreu queda acentuada na emergência, com comprometimento do estande inicial, que foi de 173 e 40 plântulas. Esse fato vem confirmar resultados de outros pesquisadores unânimes ao afirmarem o efeito benéfico do tratamento de sementes com fungicida na emergência das plantas, como Gilioli et al. (1981), Peske $\&$ Delouche (1985) e Pereira et al. (1993). Esses resultados podem ser explicados por uma série de eventos metabólicos que ocorrem no processo de germinação da semente, resultando na transformação de um embrião em plântula, fenômeno biológico cujá ocorrência é condicionada por um conjunto de condições ambientais favoráveis, sendo a disponibilidade de água de fundamental importância (Rosseto,1995). 
Embora a água seja um dos componentes mais importantes para o desenvolvimento das plantas, em condições de campo, seu suprimento nem sempre ocorre de forma ideal. $\mathrm{O}$ estresse hídrico pode afetar a germinação de sementes pelo atraso na iniciação da germinação e, conseqüentemente, proporcionar maior deterioração das mesmas por ataques de microorganismos, como fungos, presentes não só no solo, mas na própria semente. Isso demonstra que o baixo potencial de água no solo torna o processo germinativo mais lento, expondo a semente a agentes patogênicos, reduzindo consideravelmente o estande inicial. É importante ressaltar que, no caso da soja, essa situação é mais agravante, pois a mesma necessita absorver cerca de $50 \%$ do seu peso em água para que o processo de germinação se inicie.

$\mathrm{O}$ estande final observado pode ser considerado como uma continuidade do estande inicial, porém com diferenças menos pronunciadas, uma vez que, após o desbaste, a ação do tratamento da semente é menor, o que pode ser observado na Tabela 2 , na qual se constata similaridade entre tratado e não tratado para 0 e 7 dias de plantio no seco.

É interessante ainda observar que apesar das diferenças significativas constatadas para o estande final, o rendimento de grãos foi pouco alterado, pois somente o período de armazenamento de 21 dias trouxe perdas significativas nessa característica. Esse fato é, até certo ponto, normal na cultura da soja, que apresenta o aspecto da compensação, sendo traduzido por um aumento no número de ramificações para aquelas plantas que se encontram em menor densidade, apresentando, assim, maior rendimento individual, compensando os menores números de plantas na fileira. Esses resultados são comprovados por alguns pesquisadores, que relatam ausência de resposta da cultura ao aumento da densidade de plantio (Bueno, 1970, Cardoso \& Rezende, 1987 e Tourino, 2000).

\section{Altura da planta, inserção da $1^{\text {a }}$ vagem e a- camamento}

A altura da planta não foi influenciada significativamente por nenhum dos tratamentos testados, o mesmo não se verificou em relação à altura de inserção da $1^{\underline{a}}$ vagem, que apresentou efeito significativo para períodos de dias, tratamento fungicida e interação período de seca $\mathrm{x}$ tratamento fungicida (Tabela 1).

A interação período de dias $\mathrm{x}$ tratamento fungicida, depois de desdobrada, mostrou alturas de inserção de $1^{\text {a }}$ vagem mais elevadas na testemunha e nos períodos de seca de 7 e 14 dias. Essa tendência observada é até certo ponto explicada pelo fato de que nesses tra- tamentos foi verificada maior altura da planta que, conseqüentemente, eleva também a inserção da $1^{\text {a }}$ vagem (Tabela 2). Outro ponto a considerar é que tanto a altura da planta, como altura de inserção de $1^{\underline{a}}$ vagem e acamamento, apresentam-se dentro do contexto geral como ideais para colheita mecânica. É importante ressaltar que para o índice de acamamento, não foram observadas diferenças entre as médias das diferentes parcelas (todas com nota 1), razão pela qual essa característica não foi apresentada na Tabela 2 .

\section{CONCLUSÕES}

a) Semeadura da soja pode ser realizada em solo seco, mantendo-se essa semente viável por um período de até 14 dias, sem prejuízo para o rendimento de grãos.

b) $\mathrm{O}$ estande inicial e final, apesar de serem alterados significativamente pelo período seco, apresentamse dentro dos padrões recomendados de densidade, exceto para o tratamento de 21 dias, que apresentou queda acentuada.

c) A altura da planta não foi influenciada significativamente pelos tratamentos testados, o mesmo não se verificando para altura de inserção da $1^{\underline{a}}$ vagem, que foi alterada significativamente por todos tratamentos testados.

d) $\mathrm{O}$ tratamento fungicida alterou significativamente apenas o estande inicial, final e altura de inserção da $1^{-}$vagem.

\section{REFERENCIAL BIBLIOGRÁFICO}

ADKINS, S. W.; BOERSMA, M.; LAW, M. Relationship between vigour tests and emergence of soybean when grown under a range of seedbed moisture conditions. Australian Journal of Experimental Agriculture, Melbourne, v. 36, p. 93-97, 1996.

ATHOW, K. L.; CALDWELL. R. M. The influence of seed treatment and planting rate on the emergence and yield of soybeans. Phytopathology, Saint Paul, v. 46, n. 2, p. 91-95, 1976.

BERNARD, R. L.; CHAMBERLAIN, D. W.; LAWRENCE, R. E. Results of the cooperative uniform soybean tests. Washington: USDA, 1965. $134 \mathrm{p}$.

BRITO, C. H. de; BRACCINI, A. de L. e; ACOSTA, A. da S.; ALVARENGA, E. M. Efeito do dano mecânico na semente, umidade do solo e uso de óleo mineral sobre a emergência de plântulas de soja [Glycine max 
(L.) Merrill). Revista Ceres, Viçosa, v. 43, n. 250, p. 720-730, 1996.

BRASIL. Ministério da Agricultura e Reforma Agrária. Normas climatológicas: 1961-1900. Brasília: MARA, 1992. $84 \mathrm{p}$.

BUENO, L. C. de S. Efeitos de espaçamento, densidade e época de plantio sobre duas cultivares de soja. 1970.51 p. Dissertação (Mestrado) - Universidade Federal de Viçosa, Viçosa.

CARBONELL, S. A. M.; KRZYZANOWSKI, F. C. Dano mecânico em soja, um problema que poderá ser resolvido com cultivares resistentes. Inf. ABRATES, v. 3, p. 32-37, 1993.

CARDOSO, D. D. B.; REZENDE, P. M. de. Arranjo de plantas. I. Efeito do espaçamento e da densidade no rendimento de grãos e outras características da soja. Ciência e Prática, Lavras, v. 11, n. 1, p. 23-33, 1987.

COMISSÃO DE FERTILIZANTES DO SOLO ESTADO DE MINAS GERAIS. Recomendações para o uso de corretivos e fertilizantes em Minas Gerais; 4 aproximação. Viçosa, 1989. 159 p.

ELLIS, M. A.; PASCHAL, E. H. Effect of three fungicides on internally seed-borne fungi and germination of soybean seeds. Phytopatology, Saint Paul, v. 65, n. 5, p. 553-555, 1975.

FALIVENE, S. M .P.; MIRANDA, M. A. C. de; ALMEIDA, L. D. de. Temperatura e ocorrência de necrose dos cotilédones em soja. Revista Brasileira de Sementes, Brasília, v. 2, n. 2, p. 43-51, 1980.

GILIOLI, L.; PEREIRA, L. A. G.; ALMEIDA, A. M. R.; COSTA, N. P. Efeito da profundidade de semeadura e do tratamento de sementes de soja com fungicidas, sobre a emergência em solos com diferentes condições de umidade. Fitopatologia Brasileira, v. 6, n. 1, p. 8792,1981

HELMS, T. C.; DECKARD, E. L.;GOOS, R. J.; ENZ, J. W. Soil moisture, temperature, and drying influence on soybean emergence. Agronomy Journal, Madison, v. 88 , p. $662-667,1996$.

HENNING, A. A.; KRZYZANOWSKI, F. C.; FRANÇA NETO, J. B.; YORINORI, J. T. Tratamento de sementes de soja com fungicida. Londrina: EMBRAPA-CNPSo, 1991. 4 p. (EMBRAPA-CNPSo. Comunicado Técnico, 49).
MAGGIONE, C. S.; LAM-SANCHEZ, A. Efeito do tratamento de sementes com thiabendazol em formulações simples e combinadas com Captan, na germinação e nodulação da soja (Glycine max L. Merrill). Científica, Jaboticabal, v. 4, n. 2, p. 107-113, 1976.

MIRANDA, M. A. C. de; BULISANI, E. A.; ALMEIDA, L. D. de; FALIVENE, S. M. P. Efeito do período de exposição a $48^{\circ} \mathrm{C}$ na germinação e ocorrência de necrose dos cotilédones em cultivares de soja. Revista Brasileira de Sementes, Brasília, v. 1, n. 2, p. 85-92, 1979.

MORAES, M. B. L. Efeito da velocidade e da posição do impacto na germinação e no vigor de sementes de soja (Cultivar UFV-2) com diferentes teores de umidade. 1980. 42 p. Dissertação (Mestrado) - Universidade Federal de Viçosa, Viçosa.

NASSER, L. C. B.; ANJOS JUNIOR, N.; PERES, J. R. R.; MEDEIROS, A. C. S.; SPEHAR, C. R.; URBEN FILHO, G.; SOUZA, P. I. M. Fungicidas para o tratamento de sementes de soja [Glycine $\max (\mathrm{L}$.) Merrill]. Planaltina: EMBRAPA-CPAC, 1984. (Comunicado Técnico,40)

PEREIRA, L. A. G; COSTA, N. P. da; ALMEIDA, A. M. R.;FRANÇA NETO, J. de B.; GILIOLI, J. L.; HENNING, A. A. Tratamento de sementes de soja com fungicida e/ou antibiótico, sob condições de semeadura em solo com baixa disponibilidade hídrica. Revista Brasileira de Sementes, Brasília, v. 15, n. 2, p. 241246,1993

PEREIRA, L. A. G.; FRANÇA NETO, J. de B.; HENNING, A. A.; COSTA, N. P. da. Estudo da deterioração da semente de soja no solo. In: CONGRESSO BRASILEIRO DE SEMENTES, 4., 1985, Brasília. Anais... Brasília: ABRATES, 1985. p. 209.

PESKE, S. T.; DELOUCHE, J. C. Semeadura de soja em condições de baixa umidade do solo. Pesquisa Agropecuária Brasileira, Brasília, v. 20, n. 1, p. 69-85, 1985.

REZENDE, P. M. de; BUENO, L. C. de; SEDIVAMA, T.; JUNQUEIRA NETTO, A.; PAULA LIMA, L. A. de; FRAGA, A. C. Épocas de desbaste em experimentos com soja (Glycine max L. Merrill) em diferentes densidades de semeadura. In: SEMINÁRIO NACIONAL DE PESQUISA DE SOJA, 2., 1981, Bra- 
sília. Anais... Londrina: EMBRAPA-CNPSo, 1981. p. 14.

ROSSETTO, C. A. V. Estudos sobre a absorção de água e o desempenho de sementes de soja. 1995.144 p. Tese (Doutorado) - Escola Superior de Agricultura "Luiz de Queirós", Piracicaba.

RUSCHEL, A.; COSTA. W. F. Fixação simbiótica do nitrogênio atmosférico em feijão (Phaseolus vulgaris L.) 3. Influência de alguns inseticidas e fungicidas. Pesquisa Agropecuária Brasileira, Rio de Janeiro, v. 1, p. 147-149, 1966.
SOAVE, J.; WETZEL, M. M. V. S. Patologia de sementes. Campinas: Fundação Cargill, 1987. 480 p.

TOURINO, M. C. C. Arranjo populacional e uniformidade de semeadura na produtividade e outras características da soja [ Glycine max (L.) Merrill]. 2000. 139 p. Tese (Doutorado) - Universidade Federal de Lavras, Lavras.

YORINORI, J. T. Doenças da soja. In: A soja no Brasil. Campinas: Fundação Cargill, 1977. p. 159-193. 